\title{
ANÁLISE DE FACETAS E OBRA FÍLMICA
}

\author{
ANÁLISIS DE FACETAS Y OBRA FÍLMICA
}

Rosa Inês de Novais Cordeiro - rosacordeiro@vm.uff.br Professora - Departamento de Ciência da Informação Universidade Federal Fluminense - UFF

Kathryn La Barre - klabarre@illinois.edu Assistant Professor - School of Library and Information Science University of Illinois at Urbana-Champaign - UIUC

\begin{abstract}
Resumo
Pesquisa no âmbito da Organização e Representação do Conhecimento de Imagens em Movimento que tem como proposta analisar e sistematizar um universo de conteúdos provenientes de filmes cinematográficos e, em consequência, da indústria audiovisual a partir da teoria analítico-sintética, ou seja, da teoria facetada, somando-se a isso a discussão de princípios da análise fílmica e a testagem da proposta na esfera da recepção, mediante experimento realizado com alunos de pós-graduação em Ciência da Informação de duas universidades (brasileira e americana). A partir do quadro teórico-conceitual aprofundado no estudo, foi realizada a pesquisa empírica, cuja testagem procurou detectar trajetórias de pensamento na leitura/análise dos filmes pelos participantes, considerando o ambiente digital de informação, além de verificar a propriedade da recepção e das singularidades cognitivas e culturais que permearam a análise/leitura dos filmes dos segmentos participantes.
\end{abstract}

\section{Palavras-chave}

Teoria analítico-sintética facetada. Análise de facetas. Análise fílmica. Indexação de filmes. Indexação de imagens em movimento. Indústria audiovisual.

\section{INTRODUÇÃO}

Este artigo tem por objetivo evidenciar parte da pesquisa que esta sendo realizada no âmbito da Organização e Representação do Conhecimento de Conteúdos de Imagens em Movimento (filmes), e acentuar a dimensão conceitual que é inerente a esse contexto.

A nossa pesquisa tem como proposta geral analisar e sistematizar um universo de conteúdos provenientes de imagens em movimento (filmes) e, em consequência, da Inf. Inf., Londrina, v. 16 n. 3, p. $180-201$, jan./ jun. 2011 
indústria audiovisual a partir da teoria analítico-sintética, ou seja, da teoria facetada, somando-se a isto a discussão de princípios da análise fílmica e a testagem de nossa proposta na esfera da recepção, mediante experimento realizado com alunos de pósgraduação em Ciência da Informação da University of Illinois at Urbana-Champaign (UIUC) e Universidade Federal Fluminense (UFF). O experimento foi realizado com os participantes, a fim de detectarmos trajetórias de pensamento na leitura-análise das obras fílmicas e os elementos da obra fílmica que eles registraram considerando o ambiente digital de uma unidade de informação, além de verificar a qualidade/propriedade da recepção e das diferenças, em particular, cognitivas e culturais, que permearam os segmentos participantes. Entretanto, a pesquisa empírica só foi realizada partir da apreensão e do aprofundamento do quadro teórico-conceitual e que foi potencializado através do experimento desta pesquisa.

Diante disso, nossa intenção neste artigo será apresentar alguns aspectos da pesquisa quanto ao seu quadro teórico-conceitual e preparação da pesquisa empírica.

$\mathrm{Na}$ literatura da área de Ciência da Informação, os estudos que abrangem a especialidade da Organização do Conhecimento e da Informação de Imagens, englobam, em seu escopo, os audiovisuais e, entre estes, os filmes cinematográficos, contudo abordados de forma reduzida na literatura, conforme já apontamos em artigo de revisão realizado sobre o tema (CORDEIRO, 2011) e na ocasião destacamos, entre outros trabalhos, as ponderações de Enser (2008) sobre o assunto.

Reafirmarmos aqui que usaremos a expressão "imagem em movimento", no sentido comumente usado na literatura da Ciência da Informação e em oposição à imagem parada, sem pretendermos empregar essa expressão na concepção deleuzeana. Porém, ressaltamos que em nosso estudo o recorte se faz no universo do filme, ou seja, da história transmitida com imagens em movimento.

A compreensão de aspectos singulares da análise de facetas, na ação de organização do conhecimento sobre imagens em movimento, em ambientes digitais de informação, somando-se a isto o conjunto teórico sobre análise fílmica, nos parece ser um caminho promissor para as pesquisas nessa especialidade. Pois, por meio do auxílio dos fundamentos de um modelo baseado na análise de facetas substanciadas pelos conceitos que as integram, é possível compreender as manifestações do conhecimento humano e dos fenômenos em seus vários aspectos, dimensões, categorias, características e associações, de modo a organizar e a sistematizar o conhecimento, as 
idéias/pensamentos, as coisas, assim como estruturar domínios do conhecimento e suas filiações. Por conseguinte, a "Documentação tem de classificar o que está escrito sobre esses objetos, e levar em conta não apenas os tipos naturais, mas também suas propriedades, comportamentos, interações e operações nela realizadas" (VICKERY, 1980, p. 31-33). Este autor esclarece, como bem sabemos, que um determinado objeto pode ser classificado de muitos modos e com propósitos diferentes, por exemplo, um coelho pode ser classificado como roedor, animal de pele, herbívoro, animal de estimação etc., de acordo com o ponto de vista do classificador/indexador e levando-se em conta a área de domínio do conhecimento e o contexto de uso.

Na década de 60, Vickery (1966, p. 15) assinalou os "objetivos principais de um esquema de classificação ou, na verdade, de qualquer linguagem de indexação" e que poderão ser expandidos para as atividades que visam à organização do conhecimento em ambientes de informação e documentos. Conforme o autor, um dos objetivos é normalizar a linguagem dos documentos [os seus conceitos] e, o outro, a linguagem das perguntas dos usuários para que aconteça a combinação entre os conceitos/linguagens presentes nos documentos indexados e nas perguntas dos usuários. Entendemos que o controle de vocabulário não é um objetivo de um esquema de classificação, mas sim de uma linguagem documentaria verbal, como por exemplo, os tesauros e as listas de cabeçalhos de assunto. Então, Vickery alerta que uma linguagem de indexação "serve como um dispositivo útil para o indexador na tarefa intelectual de caracterizar o conteúdo temático do documento". Em conseqüência, é "um instrumento para o pesquisador na análise e definição das perguntas" arquivadas, para a sua expansão conceitual. $O$ autor esclarece que este último propósito é usualmente esquecido.

Vickery (1966, p. 38-43) acentua que "a finalidade de um esquema [de classificação] é fornecer um mapa visual dos conceitos incluídos no esquema e suas inter-relações, ajudar tanto o indexador e o pesquisador na escolha de termos". Este autor também destaca que a análise de facetas é uma forma dessa análise conceitual. Ou seja:

Qual o conceito que ela representa?

Em qual categoria conceitual deve ser incluído o conceito?

Quais são as relações de classe entre esse conceito e outros conceitos incluídos na mesma categoria?

Estas perguntas são também relembradas e destacadas por La Barre (2010) quanto à análise de facetas. Por isso, já na década de 60 e na perspective de Vickery 
(1966, p. 10), a análise de facetas tem fornecido um conjunto de princípios e técnicas que já foram aplicados em vários campos e têm se mostrado viável e útil. O autor acrescenta que é de grande importância a sua aplicação em futuros projetos de sistemas de recuperação em áreas especiais.

La Barre (2010, p. 268) mostra na linha do tempo a evolução da Teoria Facetada de Ranganathan, da Classificação Facetada e da Análise de Facetas, seus estudiosos, o estado atual da questão e aponta o futuro desafio da Teoria de Facetas, sob três perspectivas: "(1) como conduzir a análise de facetas, (2) o papel das categorias fundamentais na técnica de análise de facetas, e (3) a relação entre a análise de facetas e a classificação por facetas". Mas, acentua o desafio da aplicação da teoria de facetas ao campo empírico, entretanto, acredita que talvez o maior desafio seja estender a dimensão da análise de facetas "que poderá ser adotada e adaptada para uso em ambientes digitais em rápido desenvolvimento como a Web Semântica".

\section{A OBRA FILMICA E A ANÁLISE DE FACETAS: DIMENSAO DE ESTUDO}

Como já observamos, nossa proposta é usar a análise de facetas para tentar compreender uma possível dimensão de análise da obra fílmica e, portanto, teremos de imediato alguns desafios se compararmos ao que Vickery (1966, p. 42) indica como os passos necessários a serem seguidos para a construção de um esquema facetado de classificação. Esses passos referem-se à demarcação do campo temático e a definição do grupo de usuários; formulação das facetas, sua estruturação e arranjo; notas de escopo; adequação da notação. Porém nossa pesquisa recorrerá aos dois primeiros itens mencionados pelo autor. Destacamos que os passos citados por Vickery foram retomados por La Barre (2010) nas suas pesquisas sobre análise de facetas.

\section{Demarcação do campo temático}

Entendemos que a demarcação do campo temático, ou seja, do campo de domínio do conhecimento a ser objeto da análise de facetas é de real importância para o estabelecimento da categoria Personalidade a qual Ranganathan (1967, p. 300) assinala como sendo muito evasiva e inefável. No caso desta pesquisa, situaremos a categoria Personalidade no campo da "Indústria Audiovisual" e o nosso objeto de estudo (os filmes) localiza-se na categoria Matéria que é uma das manifestações da categoria Personalidade, pois outras manifestações são possíveis considerando a gama de 
produtos audiovisuais (videogames, etc). Aqui devemos observar as indicações de Ranganathan (1967, p. 407) sobre a relação 'Personalidade vs Matéria', quando exemplifica a possibilidade da categoria Matéria ser uma manifestação da Personalidade em um determinado contexto de assunto.

\section{Definição do grupo de usuários}

Quanto à determinação de um grupo particular de usuários, vemos que a obra fílmica assim como outros artefatos culturais e audiovisuais, pode ser de interesse para diversos grupos de usuários e portadores de diferentes níveis de conhecimento, conforme abordamos em Cordeiro e Amancio (2006), e isto tem sido notado como uma tendência na literatura, sites, etc, isto é, o procedimento de realizar a descrição, a indexação e a recuperação dos documentos em várias "camadas", a fim de permitir o acesso a informação considerando diferentes interesses e perfis de usuários. Como exemplo, podemos citar o projeto "Folktales, Facets and FRBR" desenvolvido por Kathryn La Barre e Caroll Tilley no âmbito da Graduate School of Library and Information Science- GSLIS (UIUC), cujo projeto de pesquisa visa "três grupos distintos de usuários: acadêmicos, profissionais e leigos".

Para Vickery (1966, p. 43-44) duas perguntas devem nortear a construção de um esquema de classificação e as quais tem orientado também a nossa observação do objeto de estudo, mas levando-se em conta as suas particularidades: Que coisas ou entidades são de interesse para o grupo de usuários previstos? Que aspectos dessas entidades são de interesse?

Como respostas a essas perguntas, o autor (Vickery, 1966, p. 45) propõe alguns procedimentos que deverão ser seguidos para a análise das facetas, como o exame de uma amostra representativa do material de interesse dos usuários e que poderá ser complementada pela analise de textos nas áreas de interesse e de listas de palavras. Conclui que o resultado desse caminho será uma "uma coleção de termos que são candidatos para inclusão no esquema". A partir disso, possuiremos termos candidatos indicativos dos aspectos conceituais representativos de um determinado domínio de conhecimento e que alimentarão a sistematização das facetas e das categorias fundamentais. Logo, conforme La Barre (2006, p. 271), a partir de Vickery (1960, p. 23, 27), as "categorias fundamentais são úteis como um guia provisório na abordagem da 
análise de um novo campo fornece [ndo] um quadro resumo e da[ndo] orientação ao sugerir possíveis características que não devem ser negligenciadas" ${ }^{\prime 1}$.

La Barre (2006, p. 245) alerta que encontramos na literatura diversas listas de categorias fundamentais. Pois, essas listas visam servir:

[...] como um ponto de partida preliminar (não prescritivo) para aplicação da análise de facetas para um conjunto de entidades em determinado domínio. Qualquer listagem de tais categorias fundamentais deve ser adaptada para refletir os interesses dos usuários, o conhecimento de domínio e as características das entidades em análise.

Retornando a proposta de Vickery sobre a coleção de termos resultantes da literatura para a sistematização das facetas, no caso desta pesquisa, devemos considerar algumas singularidades.

As facetas e os focos relacionados ao conteúdo de um filme (Categoria: Matéria) tiveram como fundamento os estudos existentes na literatura sobre a análise fílmica e, em especial, os trabalhos de Aumont.

Outra possibilidade que poderíamos ter aplicado, mas não foi intenção desta pesquisa e que já abordamos em outro estudo (CORDEIRO, 2000), é a possibilidade de enfocar o filme e sua família de documentos, isto é, os documentos gerados nos diversos suportes para a produção de um filme (argumento, sinopse, roteiro, storyboard, análise técnica do roteiro, etc.). Uma terceira possibilidade seria verificar as publicações (artigos, dissertações, teses, livros, etc) que abordam determinados filmes em suas análises.

\section{A OBRA FÍLMICA FACETADA: PRIMEIRAS REFLEXÕES}

A seguir apresentamos as considerações iniciais sobre a sistematização do nosso objeto de estudo, a obra fílmica, a partir da análise de facetas. Para isto, as categorias eleitas foram as propostas por Ranganathan, contudo aplicamos a seguinte ordem de citação: Personalidade, Energia, Matéria, Espaço e Tempo.

\section{a) Sobre a Categoria Personalidade - Faceta: Indústria Audiovisual}

Neste momento, duas observações se fazem necessárias quanto à obra fílmica e sua área de domínio. O campo temático a que está sujeita a obra fílmica é bastante aberto, tendo interfaces com várias áreas do conhecimento, embora tenha sua especificidade limitada à área das operações expressivas da Imagem e do Som. Esta

\footnotetext{
${ }^{1}$ Pontuação consta da citação.
} 
área, chamada de cinema e audiovisual, está inserida no domínio da Indústria Audiovisual e compreende quatro perspectivas de realização: artística, tecnológica, midiática e econômica.

No Brasil, as instituições públicas federais de pesquisa e de ensino da pósgraduação, $\mathrm{CNPq}^{2}$ e $\mathrm{CAPES}^{3}$, classificam a área de Cinema como subordinada à grande área Artes no que concerne à pesquisa. Entretanto, os cursos de pós-graduação (mestrado e doutorado) que abrigam estudos em Cinema, estão classificados na área da Comunicação, fazendo parte da grande área Ciências Sociais Aplicadas.

Esta duplicidade revela, para além da amplitude do campo, a dificuldade de classificação de uma atividade que é lida, ao mesmo tempo, como arte e indústria. Esta situação pode ser compreendida nas palavras de Getino (2006, p. 8) quando comenta o campo de trabalho e de pesquisa do profissional da área.

A visão do cinema desde o profissional, seja este empresário, autor ou
técnico, é geralmente limitada ao campo específico do setor, que vão desde
preocupações sobre o financiamento de suas próprias produções, a solução
técnica para a realização ou o esforço criativo e poético no projeto e na
construção de cada filme. O profissional é muitas vezes inserido, como
acontece em muitas outras áreas da cultura, em uma espécie de campo,
não intelectual, mas cinematográfico, movendo-se dentro de suas próprias
lógicas e relações - críticas, festivais, academias, mercados, competências
profissionais, etc.

Nesta pesquisa usaremos a expressão Indústria Audiovisual, mas devemos ressaltar o emprego também na literatura do termo "Espaço Audiovisual", que teve a sua origem nos estudos da Comissão Européia (1988). Crusafon (1999, p. 4) cita que este esse espaço situa-se "[...] na interseção da cultura, da economia e da alta tecnologia". Getino (1998, p. 11) situa também no espaço audiovisual os conteúdos simbólicos, por meio dos quais se expressam aspectos essenciais da identidade cultural de cada comunidade. De modo a estimular o "intercâmbio entre os povos e as culturas e promover um verdadeiro e democrático multiculturalismo".

Silva (2009, p. 14) define a expressão indústria audiovisual tendo em vista o cenário brasileiro, mas acreditamos que esse conceito pode ser entendido no espaço global. Portanto,

[...] a indústria audiovisual organiza-se pelo conjunto dos processos e suas interrelações, voltados para as atividades de produção, distribuição e exibição de obras elaboradas a partir do registro combinado de imagens em movimento e sons, em qualquer suporte, fotoquímicos ou eletrônicos, analógicos ou digitais.

\footnotetext{
${ }^{2}$ Conselho Nacional de Desenvolvimento Científico e Tecnológico.

${ }^{3}$ Coordenação de Aperfeiçoamento de Pessoal de Nível Superior.
} 
Este autor ainda acrescenta que " o cinema é tomado de forma integral, como resultante também de um conjunto de relações estabelecidas especialmente nos campos institucional e tecnológico [...]".

\section{b) Sobre a Categoria Energia - Faceta: Realização Audiovisual}

Diante do que foi exposto e com base na literatura, consideramos que os autores concordam com a idéia que na Indústria Audiovisual ou no Espaço Audiovisual "atuam o conjunto das atividades que resultam na produção, distribuição, exibição e consumo de obras audiovisuais" (SILVA, 2009, p. 16). Desse modo, nesta pesquisa, sistematizamos essas atividades como integrantes da Categoria Energia, faceta Realização do Audiovisual.

Assim, Silva (2009) nomeia essas atividades (processos) como "as três tríades que representam o agrupamento das estruturas relacionais do espaço audiovisual":

- produção, distribuição e exibição (núcleo central);

- instituição, tecnologia e mercado (primeiro núcleo adjacente);

- patrimônio, formação profissional, direitos de autor (segundo núcleo adjacente).

c) Sobre a Categoria Matéria - Faceta: Produto audiovisual: Filme (Característica: Filme sonoro/ silencioso ${ }^{4}$ e curta/média/longa metragem.

Neste momento, precisamos situar o produto fílmico no âmbito da Indústria Audiovisual. Conforme Silva (2009, p. 22-24) "o cinema é a origem do audiovisual contemporâneo, por ter fornecido padrões tecnológicos, de linguagem e de organização das relações dos agentes, estruturas e sistemas da indústria audiovisual". Diante disso, o mesmo autor considera que o "filme de longa-metragem é o produto cultural por excelência resultante da indústria cinematográfica que se insere na indústria audiovisual" e atentando para uma análise do ponto de vista histórico. Entretanto, devemos acentuar que com a popularização dos meios eletrônicos de difusão, o filme de longa metragem continua sua importância na faixa do prestígio, mas tem sido "substituído" por um número alarmante e não quantificável de outras mídias e produtos audiovisuais contemporâneos (os produtos audiovisuais são resultantes do registro combinado de imagens em movimento e sons, em diferentes tipos de suporte).

\footnotetext{
${ }^{4}$ Incluímos nesta faceta também os filmes silenciosos visando o agrupamento classificatório e considerando que fazem parte do contexto da indústria audiovisual.
} 


\section{- Os Focos na faceta Produto Audiovisual: Filme}

Podemos considerar o Foco como uma manifestação ou divisão de uma faceta, uma manifestação de uma classe básica ou das categorias fundamentais relacionadas. Ranganathan (1967, p. 88) esclarece que Foco é "um termo genérico para designar qualquer isolado ou qualquer assunto". Mills $(1960$, p. 8), elucida: "dentro de uma faceta, um membro individual ou subclasse, é chamado de foco".

Na obra fílmica, os Focos estão relacionados com a análise do conteúdo dos filmes, ou seja, com a narrativa fílmica. Para a conceituação dos focos e para a categorização das informações nos campos conceituais, o aporte dos estudos de análise fílmica foram de importância singular.

\section{Análise de Facetas: INDÚSTRIA AUDIOVISUAL}

Categorias Fundamentais: Ranganathan: PMEST $\rightarrow$ Aqui: PEMST

a) Categoria Personalidade - Faceta: INDÚSTRIA AUDIOVISUAL

b) Categoria Energia - Faceta: Realização Audiovisual (produção)

c) Categoria Matéria - Faceta: Produto Audiovisual: Filme (Caracteristicas: filmes sonoros/silenciosos ${ }^{5}$; filmes: curtas, médias e longas-metragens)

- Os Focos na faceta Produto Audiovisual: Filme (Característica: Curta/Média/Longa metragem e Silencioso/Sonoro).

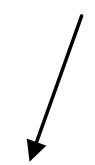

-Foco [1] na Faceta Produto Audiovisual: Filme: gênero (s)

Deve ser entendido o gênero predominante na obra fílmica. A nomenclatura usada para nomear o gênero de um filme é ampla e repleta de inovações pessoais do enunciador; assim, sugerimos que o gênero de um filme seja categorizado com base nos critérios tradicionalmente compartilhados na literatura acadêmica e técnica. $O$ sub-genêro será um desdobramento no foco 1 .

•Foco [2] na Faceta Produto Audiovisual: Filme: personagens principais

\footnotetext{
${ }^{5}$ Incluímos nesta faceta também os filmes silenciosos visando o agrupamento classificatório e considerando que fazem parte do contexto da indústria audiovisual.
} 
Protagonistas e co-protagonistas na trama. Considerar 0 antagonista e os desdobramentos necessários para demais focos, como, por exemplo, oponente, coadjuvante e figurante.

•Foco [3] na Faceta Produto Audiovisual: Filme: estrutura/unidade narrativa

Diz respeito a organização, construção do relato de uma ação, o desenvolvimento dos acontecimentos para o andamento da trama. Conforme Aumont e Marie (2003, p. 208) a narração é "Fato e maneira de contar uma história" [...]. De uma forma preliminar e ilustrativa, podemos qualificar as estruturas narrativas em simples (explicitando-se em linear, binária, circular) ou complexas (especificando-se inserção fragmentária, polifônica, aberta, oculta/ausente).

Entretanto, neste momento convém esclarecer que estamos tratando da narrativa resultante da montagem/edição do filme, mas é esclarecedor acentuar a importância também de conhecermos no universo digital o percurso traçado (as narrativas construídas) pelos usuários em seus trajetos de busca de informação na web.

•Foco [4] na Faceta Produto Audiovisual: Filme: natureza da representação da trama

É a maneira de representação, de construção da história (trama). De acordo com Aumont e Marie (2003, p. 256) "a representação, no cinema, implica na passagem de um texto, escrito ou não, à sua materialização por ações em lugares agenciados em cenografia [...]". O outro momento é a passagem dessa representação "[...] a imagem em movimento, pela escolha de enquadramentos e pela construção de uma seqüência de imagens (montagem)". Pode ser entendida como documental (realizada exclusivamente como registro documentário), reconstituída (que pretende passar por, que busca verossimilhança explicitada), aleatória (é indeterminada, não indicada expressamente no texto fílmico), mista (composta de um ou mais itens anteriormente citados). A partir disso, cabe desdobramento para outros focos.

•Foco [5] na Faceta Produto Audiovisual: Filme: referência histórica

Os fatos históricos específicos e acentuados no desenvolvimento da trama dos filmes. Os fatos podem ser classificados e desdobrados para outros focos.

•Foco [6] na Faceta Produto Audiovisual: Filme: conflito-matriz e temas representados

A partir do "conflito-matriz" os acontecimentos, as ações vão acontecendo na lógica da história, em determinado tempo e lugar, envolvendo os personagens, o ambiente físico e o 
cenário (CORDEIRO, 2000, p. 36). Os temas são os assuntos desenvolvidos no encadeamento das ações na trama e cabe desdobramento em focos.

•Foco [7] na Faceta Filme: sequências relevantes e aproximações temáticas da(s) sequência(s) escolhida(s);

São as sequências consideradas como emblemáticas para a compreensão da "proposição" da narrativa estética/poética e informativa de um determinado filme, além da possibilidade de cada uma delas ser um fragmento representativo do todo fílmico.

•Foco [8] na Faceta Produto Audiovisual: Filme: Cenografia e adereços

Estamos restringindo o sentido de cenografia como "arte de instalar cenários", (AUMONT; MARIE, 2003, p. 46). "O cenário pode ser construído para a filmagem ou existir previamente a este: fala-se então de cenário natural, quer se trate de uma filmagem no exterior ou no interior" (JOURNOT, 2005, p. 22). Ainda, no cenário tem-se a totalidade de elementos visuais (móveis, acessórios, objetos de cena, adereços, etc) que compõem o espaço onde ocorrerá a filmagem. Possibilidade de desdobramentos.

•Foco [9] na Faceta Produto Audiovisual: Filme: Figurino

Produção artística que visa projetar roupas e acessórios para a caracterização dos personagens na trama do filme. Possibilidade de desdobramentos.

•Foco [10] na Faceta Produto Audiovisual: Filme: Maquiagem

Os recursos, as substancias e as máscaras usadas para a caracterização dos personagens e efeitos fotográficos. Possibilidade de desdobramentos

•Foco [11] na Faceta Produto Audiovisual: Filme: Estúdios e Locações

Espaço onde as cenas são rodadas: estúdio e/ou locações fora de estúdios e/ou ao ar livre. Para Journot (2005, p. 58) "os estúdios constituem o complexo técnico necessário à rodagem dos filmes (oficinas, armazéns, camarins, plateau, etc). O termo designa também as empresas de produção americanas que possuem uma infra-estrutura complexa". Possibilidade de desdobramentos.

•Foco [12] na Faceta Produto Audiovisual: Filme: Efeitos Especiais

Antigamente, explica Journot (2005, p. 51-52), esses efeitos eram chamados trucagens e "designam todos os processos que permitem produzir uma imagem irrealista. Tão antigos quanto o próprio cinema [...]". A autora também esclarece que existem os efeitos especiais sonoros (resultam da reconstituição, da gravação, da filtragem, da deformação, da póssincronização e da mistura) e os efeitos especiais visuais (na cenografia, nos cenários; na 
filmagem; na tiragem; durante a revelação para os efeitos de ligação. Possibilidade de desdobramentos.

•Foco [13] na Faceta Produto Audiovisual: Filme: Som

O som que o filme oferece raramente intervém sozinho. Ele supõe um agenciamento entre vários eixos: ruídos, falas e às vezes música ${ }^{6}$. Além disso, o som fílmico e acompanhado de uma percepção visual é, portanto, áudio (verbo) visual e faz intervir combinações entre sons e imagens: redundância, contraste, sincronismo ou dessincronismo ou dessincronização, etc. Existem diversos procedimentos e fases de transformação do som antes de atingir o ouvido do auditor-espectador: mixagem, modulação, amplificação, etc (AUMONT; MARIE 2003, p. 275-276). Possibilidade de desdobramentos.

d) Sobre a Categoria Espaço [na faceta: Produto Audiovisual: filme]

Foco: Espaços (local ou lugar geográfico) representados na narrativa.

e) Sobre a Categoria Tempo [na faceta: Produto Audiovisual: filme]

Foco: Registro temporal da trama (se a narrativa acontece no tempo/período passado, na atualidade ou no futuro).

A partir das categorias, facetas e focos acima sistematizados e que podem ser desdobradas, procuramos verificar no experimento a ocorrência das mesmas nas análises dos filmes realizadas pelos participantes.

\section{A PESQUISA EMPÍRICA}

O objetivo principal da pesquisa de campo foi analisar o conteúdo das análises dos filmes realizadas e registradas pelos participantes, a fim de extrair, dessas descrições, elementos importantes registrados pelos participantes, que poderão ser considerados para melhorar a análise, a recuperação e o acesso aos filmes em uma variedade de ambientes de informação (repositórios digitais, bibliotecas e arquivos).

A pesquisa de campo tinha dois objetivos principais:

- verificar a possibilidade da aplicação da análise de facetas e análise fílmica para a interpretação e a sistematização das informações registrados pelos participantes sobre os filmes;

${ }^{6}$ ruídos, músicas, falas/diálogos/comentários, as pausas e o silêncio. 
- observar os aspectos culturais que estavam presentes nas interpretações dos filmes registradas pelos participantes, mas esses não estão sendo abordados neste artigo.

Os resultados do estudo poderão contribuir para a discussão de melhorias nas estratégias de indexação e o acesso as coleções de filmes, colaborando com os estudos que visam entender a dinâmica da interpretação do sujeito enunciador (indexadorespectador) nas narrativas fílmicas. O espectador e o texto fílmico não podem ser vistos separadamente, pois o processo de construção de sentido implica uma interação dos dois (KUHN, 1982, p. 56 apud MACHADO, 2007, p. 20). Soma-se nesta interpretação do enunciador, entre outros aspectos, a sua herança cultural que aponta para a sua maneira de ver o mundo e construir significados. Conforme Benedict a cultura é como uma lente de observação da realidade através da qual o homem vê o mundo e o particulariza ao seu universo de vivência. A partir disso, declaramos que nossa pesquisa tinha também a intenção de observar, nos grupos participantes (americanos e brasileiros), a existência ou não de influências culturais na interpretação ${ }^{7}$ dos filmes registradas pelos participantes, pois poderíamos indicar indícios a serem levados em consideração na indexação e no acesso aos filmes em ambientes de informação. Porém, sabemos

Quanto mais a vida social se torna mediada pelo mercado global de estilos, lugares e imagens, pelas viagens internacionais, pelas imagens da mídia e pelos sistemas de comunicação globalmente interligados, mais as identidades se tornam desvinculadas - desalojadas - de tempos, lugares, histórias e tradições específicos e parecem 'flutuar livremente' (HALL, 2006, p. 20).

Por outro lado, "há, juntamente com o impacto do "global", um novo interesse pelo "local". A globalização [...] na verdade, explora a diferenciação local. Assim, ao invés de pensar no global como "substituindo" o local seria mais acurado pensar numa nova articulação entre "o global" e "o local" (HALL, 2006).

\section{Amostra e Procedimentos}

Baseado no desenvolvimento do quadro teórico conceitual aprofundado durante a pesquisa e mencionado, tivemos a intenção de aumentar o potencial do estudo através do experimento realizado e, portanto, três filmes foram selecionados e foram considerados os seguintes critérios:

a) Filmes de domínio público (ou Creative Commons License);

b) A linguagem cinematográfica dos filmes.

\footnotetext{
${ }^{7}$ Mediante análise das narrativas realizadas pelos participantes sobre o filme e que foram registradas no instrumento de pesquisa nos itens sinopse, palavras-chave, outras informações sobre o filme.
} 
Filmes que ilustram uma construção narrativa: linguagem clássica (A Corner in Wheat (1909) Griffith - 13:52 - silencioso ${ }^{8}$ ); Linguagem de transição do clássico ao cinema moderno (The 39 Steps (1936) Hitchcock - sonoro- 1:32); linguagem do cinema contemporâneo (First Love (2006) Flight and Camac - silencioso -6:57);

c) Gênero (filmes de ficção);

d) A narrativa do filme (fatores cognitivos e culturais);

e) Linguagem dos participantes (a possibilidade de filmes com legendas em inglês e português e filmes silenciosos);

f) Duração dos filmes (curtas e longas);

g) Qualidade de imagem (qualidade de cópia / imagem na web).

A amostra contou com a participação de doze alunos de pós-graduação em Ciência da Informação, sendo seis alunos americanos da UIUC e seis alunos brasileiros da UFF para coleta de dados. Foi elaborado um instrumento para análise dos filmes no qual os participantes deveriam responder três solicitações sobre o filme, isto é, o seu resumo, as suas palavras-chave e outras informações que os participantes consideravam importantes para o usuário acessar o filme em um ambiente de informação. Então, os participantes deveriam preencher os formulários com os registros das análises dos filmes.

Os filmes foram vistos de forma livre/espontânea e acessando o Internet Archive Movie, mas foi seguido um cronograma previamente estabelecido entre alunos e professores. Ainda, eram objetivos desta etapa: - a validação dos parâmetros que poderiam ser propostos para a análise dos filmes; - a verificação da qualidade de recepção e as diferenças, em particular, dos fatores cognitivos e culturais que permearam os segmentos (nacionalidade), entretanto os resultados que chegamos quanto ao último objetivo citado não será abordado neste artigo.

Constavam no formulário para análise dos filmes, as seguintes solicitações aos participantes:

-Descreva um resumo da história do filme que contenha informações que você considera relevantes para o usuário de uma unidade de informação saber sobre o filme.

Nota: a extensão do resumo é livre.

\footnotetext{
${ }^{8} \mathrm{Na}$ nossa amostra usamos um filme emblemático de Griffity, de 1909, então, devemos ressaltar, que no cinema dos primeiros tempos, o cinema silencioso, eram usados, os intertítulos para a explicação da trama, além de outros recursos. Nesta época, nos espaços de exibição de filmes havia a presença sonora para o acompanhamento musical do filme que podia ser realizada, ao vivo, com a participação de um pianista ou por uma pequena orquestra.
} 
- Liste as palavras-chaves que você considera importantes para o acesso às informações do filme por um usuário de uma unidade de informação.

Nota: o número de palavras-chave é livre.

-Quais outras informações que você considera importantes de serem fornecidas a um usuário de uma unidade de informação que não foram incluídas no seu resumo? Como exemplo: som (diálogos, ruídos e musica), efeitos especiais, cenário, figurino, etc.

Nota: Os dados referentes a catalogação do filme (título, diretor, tempo de duração do filme, etc) não precisam ser incluídos, exceto se você considerar que algum desses dados apresenta alguma excepcionalidade que deverá ser ressaltada para um usuário de uma unidade de informação.

No Internet Archive Movie encontramos as fichas técnicas dos filmes e suas sinopses, porém no mesmo site outras informações sobre os filmes poderiam ser acessadas. Incluímos, também, a seguir, as sinopses sobre os filmes que estavam disponibilizadas no site Internet Movie Data Base (IMDb) ${ }^{9}$.

\section{a) A Corner in Wheat}

-Ficha técnica e sinopse do filme a partir das informações disponíveis no Internet Archive Movie ${ }^{10}$ :

Produtor: D.W. Griffith

Audio/Visual: som, cor. Filme silencioso.

Palavras-chave: D.W.; DW; Griffith; A; Corner; in; Wheat; 1909; Importante; Lendário;

Clássico; Inovador; Bom; Filme; Cinema, História, Histórico, Social; Comentário; América; Americana; Eterno; Único; Antigo; De época; Nacional; Filme; Registro ("Registry"); Biblioteca; de; Congresso. Carece esclarecer que as palavras- chave são descritas de forma livre.

Creative Commons License: Domínio Público.

Sinopse:

A Corner in Wheat é um filme curta de 1909 sobre um magnata ganancioso que tenta enriquecer no mercado mundial de trigo, destruindo as vidas das pessoas que não podem pagar para comprar pão. Foi dirigido por D.W. Griffith e adaptado por Griffith e Frank Woods, a partir do romance The Pit (1903) de Frank Norris. Este é o primeiro filme

\footnotetext{
${ }^{9}$ Internet Movie Data Base. Disponível em: < http://www.imdb.com/>. Acesso em: 20 jul. 2011.

${ }^{10}$ Internet Archive Movie. Disponível em: <http://www.archive.org/details/D.w.Griffith-ACornerlnWheat1909>. Acesso em: 20 jul. 2011.
} 
em que Griffith realiza tentativas de comentário social. O cenário é semelhante aos problemas dos agricultores pobres e as relações de um malfadado "Rei do Trigo". Em 1994, A Corner in Wheat foi selecionado para preservação no United States National Film Registry pela Library of Congress como sendo 'culturalmente, historicamente ou esteticamente significativos'.

-Sinopse a partir das informações disponíveis no site IMDb ${ }^{11}$.

- Um magnata ganancioso decide, por capricho, dominar o mercado mundial de trigo. Isto dobra o preço do pão, forçando os produtores de grão a caridade e a pobreza. O filme contrasta as diferenças irônicas entre a vida de quem trabalha para crescer com o trigo e a vida do homem que brinca na sua venda com o lucro.

\section{b) First Love}

-Ficha técnica e sinopse do filme a partir das informações disponíveis

no Internet Archive Movie ${ }^{12}$ :

Diretor: Scott Camac and Nick Flight

Produtor: Scott Camac and Nick Flight

Produção: Scott Camac and Nick Flight

Elenco: Isaac Camac Rebekah

Música: Greame Burgan

Audio/Visual: Filme silencioso, Música por Greame Burgan, Preto e Branco

Palavras-chave: Em primeiro lugar; Amor; Scott; Camac; Nick; Flight; Curta; Filme;Preto;

Branco; Romance; Comédia; Primeiro Amor; Filme silencioso;

Nick Flight; "Nick Flight"; Scott Camac; "Scott Camac"; Burnie; Tasmânia; Austrália. As palavras-chave foram nomeadas de forma livre.

Informação para contato: Entre em contato através do nosso blog:

www.scottcamac.blogspot.com or www.nickflight.blogspot.com or the films blog www.firstlovethemovie.blogspot.com

Creative Commons License: Uso não comercial. Vedada a criação de obras derivadas.

\section{Sinopse}

First Love é um filme sobre um jovem adolescente que procura o afeto de seu primeiro amor. Filme silencioso em preto e branco e filmado na Tasmânia, Austrália. É o primeiro

\footnotetext{
${ }^{11}$ Internet Movie Data Base. Disponível em: < http://www.imdb.com/title/tt0000832/>. Acesso em: 20 jul. 2011.

${ }^{12}$ Internet Archive Movie. Disponível em: < http://www.archive.org/details/first_love_short_film>. Acesso em: 20 jul. 2011.
} 
curta-metragem que Nick e Scott Camac trabalham juntos e são responsáveis pelo roteiro, direção e filmagem.

•Sinopse não disponível no site IMDb.

\section{c) The 39 Steps}

-Ficha técnica e sinopse do filme a partir das informações disponíveis

no Internet Archive Movie ${ }^{13}$ :

Diretor: Alfred Hitchcock

Audio/Visual: Sonoro, preto e branco

Idioma:Inglês

Palavras-chave: LivingBorough; Alfred Hitchcock; The 39 Steps; Kensington and Chelsesa;

Creative Commons License: Uso não Comercial - Vedada a criação de obras derivadas 3.0 .

\section{Sinopse:}

The 39 Steps é um thriller britânico de 1935, dirigido por Alfred Hitchcock, baseado na obra homônima de John Buchan. O filme é estrelado por Robert Donat e Madeline Carrol. -Sinopse do filme a partir das informações disponíveis no site IMDb ${ }^{14}$.

Um homem em Londres tenta ajudar uma agente secreta sobre um caso de espionagem. Mas a agente é assassinada e o homem acusado de ser o assassino da mulher, então, ele decide resolver o mistério para salvar a si mesmo, pois é perseguido tanto pela polícia, que acredita ser ele o assassino, quanto é caçado pelos espiões que acham que ele sabe demais.

\section{DISCUSSÃO E CONSIDERAÇÕES FINAIS}

No que concerne as categorias, as facetas e os focos, tivemos como parâmetros para a análise das interpretações dos participantes sobre os filmes o exame da ocorrência ou não das categorias Matéria, Espaço e Tempo, além dos treze Focos da Faceta Produto Audiovisual: Filme.

\footnotetext{
${ }^{13}$ Internet Archive Movie. Disponível em: <http://www.archive.org/details/AlfredHitchcocksthe39Steps1935>. Acesso em: 20 jul. 2011.

${ }_{14}$ Internet Movie Data Base. Disponível em: <http://www.imdb.com/title/tt0026029/>. Acesso em: 20 jul. 2011.
} 
Embora, não seja abordado neste artigo, também verificou-se a ocorrência de elementos que apontassem para representações de aspectos culturais dos dois segmentos participantes (brasileiros e americanos). A partir das ideias de Gerrtz, diríamos que, no espaço da cultura, os registros gerados pelos participantes e resultantes da leitura dos filmes, podem ser entendidos como "veículos materiais da percepção, da emoção e da compreensão" de símbolos significantes.

A seguir, apresentamos os resultados da análise dos filmes quanto aplicação das categorias, faceta [Produto Audiovisual-Filme] e focos.

\section{a) A Corner in Wheat}

-Principais categorias e focos usados pelos participantes para a análise do filme.

Categoria Matéria

Foco [6] na Faceta Produto Audiovisual-Filme: conflito-matriz e temas representados .

Foco [2] na Faceta Produto Audiovisual-Filme: personagens principais.

Foco [13] na Faceta Produto Audiovisual-Filme: som [silencioso e intertítulos]

Categoria Tempo

b) First Love

- Principais categorias e focos usados pelos participantes para a análise do filme.

Categoria Matéria

Foco [6] na Faceta Produto Audiovisual-Filme: conflito-matriz e temas representados.

Foco [2] na Faceta Produto Audiovisual-Filme: personagens principais.

Foco [1] na Faceta Produto Audiovisual-Filme: gênero.

Foco [13] na Faceta Produto Audiovisual-Filme: som [silencioso e intertítulos]

Categoria Tempo

c) The 39 Steps

- Principais categorias e focos usados pelos participantes para a análise do filme.

Categoria Matéria

Foco [6] na Faceta Produto Audiovisual-Filme: conflito-matriz e temas representados.

Foco [2] na Faceta Produto Audiovisual-Filme: personagens principais.

Foco [1] na Faceta Produto Audiovisual-Filme: gênero.

Categoria Espaço

Categoria Tempo 
Como o resultado acima demonstra e considerando a categoria Matéria, faceta Produto Audiovisual-Filme, os focos recorrentes situam-se nos aspectos referentes ao conflito-matriz e temas representados nos filmes, nos personagens principais da trama e a citação ao gênero cinematográfico. As categorias Espaço e Tempo também foram recorrentes de menção.

Acreditamos que os resultados desta fase da pesquisa confirmaram a possibilidade do uso da análise de facetas e que determinados aspectos de um filme são habitualmente acessados, mas que outros pontos de vista também podem ser analisados, indexados e acessados desde que o ambiente de informação tenha esses itens previstos de forma criteriosa para a análise do indexador, visando serem pontos de acesso aos filmes.

Entendemos que qualquer processo de análise de um objeto de estudo, inclusive o processo de análise para a classificação e indexação de filmes, deveria considerar o "paradoxo da análise"15. Assim, analisar é buscar e fornecer esclarecimentos, sem o prejuízo de alterar o objeto. A análise ("leitura") de um indexador de filmes ou de outro tipo de documento, resulta da mediação que o indexador/classificador realiza entre o universo de documentos e o universo de usuários. Como resultado dessa mediação, o indexador disponibiliza a declaração conceitual e terminológica dessas informações para os usuários como pontos de acesso aos conteúdos dos filmes ou outros documentos. Entretanto, ao contrário dos documentos textuais, as narrativas dos filmes cinematográficos são conduzidas por textos, imagens em movimento e som, essas poderiam ser privilegiadas nas preocupações do profissional de informação de audiovisuais e nos metadados para o acesso aos filmes em ambientes de informação.

\section{REFERÊNCIAS}

AUMONT, Jacques; MARIE, Michel. Á quoi pensent les filmes. Paris: Séguir, 1996.

. Dicionário teórico e crítico de cinema. Campinas, SP: Papirus, 13-15, 2003.

BORDWELL, David . Figuras traçadas na luz. Campinas, SP: Papirus, 2008.

CORDEIRO, Rosa Inês de Novais. Análise e representação dos conteúdos de imagens para o acesso à informação. In: FREITAS, LÍDIA SILVA de; RODRIGUES, Ana Célia (Org.). Documentos: gênese e contextos de uso. Niterói: EDUFF, 2010. p. 235 - 245.

\footnotetext{
${ }^{15}$ Ou seja, a análise não deve trazer alteração no objeto analisado, embora deva levar a alguma alteração no sujeito, pois a análise o leva a compreender melhor o que antes lhe parecia mais obscuro e confuso. Cf. LEWIS ; C. H. LANFORD
} 
. Imagem e movimento. Rio de Janeiro: UFF: Programa de Pós-Graduação em Ciência da Arte, 2000.

; Amâncio, Tunico. Análise e representação de filmes em unidades de informação. Ciência da Informação, v.34, n.1, p. 89-94, 2005.

O que vemos e como vemos: do ponto de vista do sujeito receptor. In: ENCONTRO NACIONAL DE PESQUISA EM CIEENCIA DA INFORMAÇÃO, 7., 2006, Marília. Anais...Marília : FFC/UNESP-PUBLICAÇÕES, 2006.

CRUSAFON BAQUES, Carmina . El espacio audiovisual europeo: analiss de la industria auidiovisual y de las politicas europeas en la decada de los 90. 1999.

(Tese) - Universidad Autonoma de Barcelona, Barcelona, 1999.

ENSER, Peter. The evolution of visual information retrieval. JIS, v. 34, n. 4, p. 531-546, 2008a.

. Visual imagem retrieval. ARIST, v. 42, p. 3-91, 2008b.

GETINO, Octavio .Cine y television en America Latina: prodduccion y mercados.Santiago de Chile: Lom Ed., Universidad ARCIS, Fundacion del Nuevo Cine Latinoamericano, 1998.

. Entrevista. Revista Eptic Online, n. 2, p. 8-15, 2006.

HALL, Stuart. A identidade cultural na pós-modernidade. Rio de Janeiro: DP\&A.Hertzum, 2006.

JOURNOT, Marie-Thérèse. Vocabulário de cinema. Lisboa: Edições 70, 2005.

JULLIER, Laurent; MARIE, Michel. Lendo as imagens do cinema. São Paulo: Ed. Senac, 2009.

LA BARRE, Kathryn. Facet analysis. ARIST, v. 44, p. 243-284, 2010.

. Faceted navigation and browsing features in new OPACs. Knowledge Organization, v. 34, n. 2, p. 78-90, 2007.

. The heritage of early faceted classification in document reference retrieval system, 120-1969. Library History, v. 23, n. 2, p. 129-149, June, 2007.

. The use of faceted analytic-synthetic theory as revealed in the practice of website construction and design. 2006. 333f. Tese (Doctor of Philosophy), School of Library and Information Science, Indiana University, 2006.

MACHADO, Arlindo. O sujeito na tela: modos de enunciação no cinema e no ciberespaço. São Paulo: Paulus, 2007.

MILLS, J. A modern outline of library classification. London: Chpman \& Hall, 1960.

Faceted classification and logical division in information retrieval.

Library Trends, v.52, n.3, p. 541-570, 2004. 
RANGANATHAN, S. R. The Colon Classification. New Brunswick, NJ: Graduate School of Library Science, Rutgers University, 1965.

, S. R. Prolegomena to library classification.3.ed. Bombay: Asia

Publishing House, 1967.

SILVA, João Guilherme Barone Reis. Comunicação e indústria audiovisual:

cenários tecnológicos e institucionais do cinema brasileiro na década de 90. Porto Alegre: Sulina, 2009.

VANOYE, Francis; GOLIOT-LETÉ, Anne. Ensaio sobre a análise fílmica. Campinas, SP: Papirus, 1994.

VICKERY, B. C. Faceted classification: a guide to construction and use of special schemes. London: Aslib, 1960.

Faceted classification schemes. New Brunswick, NJ: Graduate

School Library Science, Rutgers the State University, 1966.

. Classificação e indexação nas ciências. Rio de Janeiro: BNG/Brasilart, 1980.

\title{
Title
}

Facet analysis and filmic work

\begin{abstract}
This is a research within the scope of the Organization and Representation of Knowledge of Motion Pictures with the purpose of analyzing and systematizing a universe of content from films, and as a result, of the audiovisual industry based on the analytical-synthetic theory, i.e., of the faceted theory, as well as the discussion of principles of filmic analysis and the testing of the proposal in the reception scope, by means of an experiment with graduate students in Information Science from two universities (Brazilian and American). Based on the in-depth theoretical-conceptual framework of this study, an empirical research was carried out, which sought to detect trajectories of thought in the reading / analysis of the films by the participants, considering the digital environment of information and to check the property of reception and the cognitive and cultural singularities that permeated the analysis / reading of the films of the participating segments.
\end{abstract}

\section{Keywords}

Faceted analytic-synthetic theory. Facet analysis. Filmic analysis. Indexation of films. Indexation of moving images. Audiovisual industry.

\section{Título}

Análisis de facetas y obra fílmica 


\section{Resumen}

Este trabajo se basa en la investigación en el ámbito de la Organización y Representación del Conocimiento de Imágenes en Movimiento cuya propuesta es la de analizar y sistematizar un universo de contenidos provenientes de películas cinematográficas y, consecuentemente, de la industria audiovisual a partir de la teoría analítico-sintética, es decir, de una teoría de facetas, sumándose a esto la discusión de principios de análisis fílmico y la prueba de la propuesta en la esfera de la recepción, mediante un experimento realizado con alumnos de postgrado en Ciencias de la Información de dos universidades (brasileña y americana). A partir del cuadro teórico conceptual profundizado en el estudio, se realizó la investigación empírica, cuya prueba buscó detectar trayectorias de pensamiento en la lectura-análisis de las películas que realizan los participantes, considerando el ambiente digital de información, además de verificar la propiedad de la recepción y de las singularidades cognitivas y culturales que permearon el análisis/lectura de las películas por partes de los participantes.

\section{Palabras clave}

Teoría analítico-sintética facetada. Análisis de facetas. Análisis fílmico. Indexación de películas. Indexación de imágenes en movimiento. Industria audiovisual.

Recebido em: 21/11/2011

Aceito em: 07/12/2011 